\title{
Sedimentation analysis of columnar ice crystals in viscous flow regimes
}

\author{
Rodrigo Exequiel Bürgesser ${ }^{1,3} \mid$ Juan Pablo Giovacchini ${ }^{2}$ | Nesvit Edit Castellano ${ }^{1,3}$
}

${ }^{1}$ Group of Atmospheric Physic, FaMAF, Universidad Nacional de Córdoba,

Córdoba, Argentina

${ }^{2}$ Departamento de Mecánica Aeronáutica, Centro Regional Universitario

Córdoba - IUA, Universidad de la Defensa Nacional, Córdoba, Argentina

${ }^{3}$ Instituto de Física Enrique

Gaviola(CONICET), Córdoba, Argentina

\section{Correspondence}

*R. E. Bürgesser, FaMAF, Av. Medina Allende $\mathrm{s} / \mathrm{n}$, Ciudad Universitaria, $\mathrm{CP}$ X5000HUA Córdoba, Argentina. Email:burgesse@famaf.unc.edu.ar

\section{Funding information}

Secretaría de Ciencia y Tecnología de la Universidad Nacional de Córdoba

\begin{abstract}
The sedimentation process of columnar ice crystals was evaluated using data obtained by the lattice Boltzmann method. The data used correspond to columnar ice crystals with maximum dimension less than $100 \mu \mathrm{m}$ and aspect ratios between 1 and 3 . The terminal velocity was computed for different ice-crystal bulk densities and for three falling orientations. The analysis corresponds to ice crystals falling in viscous flow regimes, where theoretical formulations overestimate the terminal velocity. Different characteristic lengths of columnar ice crystals and different theoretical proposals for the sedimentation process were tested in order to find the best representation of the data. Characteristic lengths reported in the literature do not represent the sedimentation process for all the falling orientations used in this study. Thus, it was not possible to obtain a unique relation between the Best and Reynolds numbers. In particular, columnar ice crystals falling with their longer dimension parallel to the vertical direction show a large dispersion that it does not seem possible to reduce. The theoretical and semi-empirical formulations of the terminal velocity evaluated show large deviations in the computed velocity, with a strong dependence on ice-crystal aspect ratio. The dispersion observed seems to be intrinsically related to the dimensionless variables used to parametrize the terminal velocity. To derive a unique scale law that could represent the sedimentation process of ice crystals, geometric, kinematic, and dynamic similarities are required. However, these conditions are not fulfilled in the sedimentation process.
\end{abstract}

\section{K E Y W O R D S}

characteristic length, columnar ice crystals, lattice Boltzmann method, sedimentation process, viscous flow regimes

\section{1 | INTRODUCTION}

Given the relevant role of the sedimentation process of solid precipitation particles in the temporal evolution of

Equally contributing authors. clouds and in different microphysical processes occurring within them (Pruppacher and Klett, 1997), numerous investigations of this process have been reported in the literature (Böhm, 1989, 1992; Mitchell, 1996; Heymsfield and Westbrook, 2010; among others). These different studies concluded that the mass and cross-sectional area that the 
particle presents to the flow are the primary variables that determine the terminal velocity of ice particles.

Usually, a functional dependence of the drag coefficient $\left(C_{\mathrm{D}}\right)$ on the Reynolds number $(R e)$ has been proposed to parametrize the sedimentation process (Jayaweera and Cottis, 1969; Kajikawa, 1971; List and Schemenauer, 1971; Mitchell, 1996; Khvorostyanov and Curry, 2002; 2005; Mitchell and Heymsfield, 2005; Heymsfield and Westbrook, 2010, among others).

$R e$ is a dimensionless quantity defined as the ratio between inertial forces and viscous forces within a fluid. Therefore, the value of Re determines the behavior and characteristics of the flow patterns. In order to compute $R e$, it is necessary to define a characteristic length $D$ for the falling particle of interest. This characteristic length represents the typical dimension of the particle in the fluid medium.

Ice particles are nonspherical particles and therefore defining their characteristic length has been challenging. Bailey and Hallett (2004) showed that the shape of crystals is related to temperature, oversaturation, and the initial nucleation process. These researchers reported that the low supersaturation habit is characterized by polycrystals and is essentially independent of temperature in the temperature range between -20 and $-70^{\circ} \mathrm{C}$. In addition, measurements of ice crystals collected in natural clouds (Korolev et al., 1999; 2000; Um et al., 2015; Lawson et al., 2019) reported a dominance of irregular particles. However, given the hexagonal lattice structure of water molecules in ice, a hexagonal prism is the fundamental shape of nucleated ice crystals before other growth processes, such as sublimation, aggregation, and riming, occur.

Several proposals have been made to define the value of $D$ for ice crystals. For instance, Mitchell (1996) proposed the maximum dimension of the ice crystal as its characteristic dimension, Böhm (1992) proposed the diameter of the smallest circle or ellipse that completely contains the cross-sectional area that the particle presents to the flow, and Westbrook (2008) proposed the ice crystal capacitance as its characteristic length.

Using the different proposals for $D$, various functional expressions have been obtained for $C_{\mathrm{D}}$ as a function of $R e$. Therefore, knowing the ice particle properties (size and mass) and fluid properties, the terminal velocity of ice particles can be computed.

In general, these formulations take into account the falling orientations of hexagonal ice crystals through the transverse area presented by the ice crystal to the fluid. Using this approach, Böhm (1992) indicated an error of less than $10 \%$ in the terminal velocity and drag coefficient of solid hydrometeors. However, the calculated velocities using the different formulations could show larger errors. For instance, Mitchell (1996) reported an accuracy of within $20 \%$ in the calculated velocity using his parametrization, while Westbrook (2008) reported that the proposals of Mitchell (1996), Khvorostyanov and Curry (2002), Khvorostyanov and Curry (2005), and Mitchell and Heymsfield (2005) overestimate the experimental data by around 50\% for columnar ice crystals with an aspect ratio of 1.5. Westbrook (2008), using the theoretical treatment proposed by Hubbard and Douglas (1993), reported an agreement between the experimental observation and the computed velocity of within $\sim 20 \%$.

These discrepancies between experimental data and the theoretical approach could lead to an overestimation of the sedimentation rate for ice crystals with maximum dimensions less than $100 \mu \mathrm{m}$ (Westbrook, 2008). These small ice crystals play a key role in cirrus clouds, which in turn make an important contribution to the radiation budget of the Earth. The net effect of cirrus clouds on the radiation budget depends on the size and shape of the ice particles forming the clouds. For instance, ice particle shapes and sizes determine the ice water content and terminal velocity of ice particles and also the scattering properties of this type of cloud (Baran, 2009). Climate models are sensitive to the parametrizations that represent the ice process occurring in clouds (Manning and Davis, 1997; Jakob, 2002; Hong et al., 2004; Deng and Mace, 2008; Mitchell et al., 2008; Sanderson et al., 2008). Jakob (2002) found that large changes in cirrus ice water path and long-wave cloud forcing are directly related to changes in the ice fall speed. Sanderson et al. (2008) showed that the ice fall speed is the second most influential parameter in climate models. Finally, the terminal velocity controls the cloud coverage and lifetime, both of which affect the total radiative impact of cirrus clouds (Spichtinger and Gierens, 2009).

Although there are some controversies about the high concentration of ice particles with sizes less than $60 \mu \mathrm{m}$ in ice clouds measured in situ (Heymsfield, 2007; McFarquhar et al., 2007; Westbrook and Illingworth, 2009), the use of probes with Korolev tips (Korolev, 2011) ${ }^{1}$ and the use of algorithms to correct the data collected (see for instance Lawson, 2011) reduce the impact of shattered artifacts on the in situ measured data. Baker and Lawson (2006) reported a particle size distribution weighted by number between $\sim 10^{2}$ and $10^{4} \mathrm{~L}^{-1} \mu \mathrm{m}^{-1}$ for ice-particle lengths less than $100 \mu \mathrm{m}$ and an aspect ratio between 1 and 4 for pristine columns in wave cloud. Um et al. (2015) reported a large number of columnar ice crystals with maximum dimension less than $100 \mu \mathrm{m}$ and aspect

\footnotetext{
${ }^{1}$ United States Patent No. 7861 584, Issued: 4 January 2011, Owner: Her Majesty the Queen in Right of Canada, as Represented by The Minister of Environment.
} 
ratio between 1 and 3 for temperatures below $-40^{\circ} \mathrm{C}$. Jackson et al. (2015) applied an approach to identify multiple modes in the size distribution of data from cirrus cloud and found that small ice crystals with maximum dimension less than $60 \mu \mathrm{m}$ make a substantial contribution to the total ice concentration of convective cirrus. Luebke et al. (2016) analyzed the dataset from the ML-CIRRUS campaign (Voigt et al., 2017) and showed that the median size of ice crystals contributing the most mass is less than $200 \mu \mathrm{m}$ for in-situ origin cirrus (Kraemer et al., 2016).

Given the sensitivity of the climate models to the schemes of the ice processes used, the errors in the calculated velocities for small ice crystals could lead to errors in the optical properties and lifetime cycle of cirrus cloud forecast by the models. Generally, the errors in the calculated velocities are attributed to the large dispersion of the experimental data used to compute $C_{\mathrm{D}}$ and $R e$. The datasets used are from tank measurements of the drag in ice crystal models and measurements of real ice particles falling in air. Generally, the tank measurements show small experimental errors but are limited in range of ice-crystal shape. On the other hand, data measured from real ice particles present a larger dispersion and also all governing variables, such as ice-crystal mass or falling orientations, are not always measured. Therefore, a complete dataset of the governing variables is needed to develop a more precise parametrization of the sedimentation process.

Giovacchini (2017) presented a numerical tool to study the sedimentation process using the lattice Boltzmann method (LBM). This method facilitates the computation of the terminal velocity of ice crystals once their size, aspect ratio, mass, and falling orientation, as well as the fluid properties, are known. The results reported by Giovacchini (2017) have shown good agreement with experimental data (Jayaweera and Ryan, 1972; Kajikawa, 1973; Bürgesser et al., 2016) and theoretical results (Westbrook, 2008), which demonstrates that LBM is a powerful tool to study the sedimentation process of ice crystals. The data provided by LBM have the advantage that all governing variables are well defined and available to study this process.

The goal of this work is to determine which characteristic dimension allows an adequate parametrization of the terminal velocity of ice crystals. For this purpose, the present study uses the data obtained by LBM to evaluate the sedimentation process of columnar ice crystals with different falling orientations and bulk densities. Although the majority of ice crystals in natural cloud present irregular shapes (Korolev et al., 1999; 2000; Um et al., 2015; Lawson et al., 2019), the study of columnar ice crystal is fundamental, given that a hexagonal column is one of the basic habits from which other ice-crystal shapes develop. In addition, several studies have proposed different characteristic lengths and parametrizations to represent the sedimentation process of columnar ice crystals based on the results of tank experiments and on observations in natural clouds. Therefore, the present analysis allows us to evaluate the influence of the characteristic lengths, which could represent the dimension of falling ice particles, and to compare the results obtained with the formulations reported in the literature.

\section{2 | THEORETICAL BACKGROUND}

When particles falling in air reach the terminal velocity $\left(v_{\mathrm{t}}\right)$, the drag force $\left(F_{\mathrm{D}}\right)$ equals the weight of the particle (the buoyancy force is neglected),

$$
F_{\mathrm{D}}=\frac{1}{2} \rho_{\text {air }} v_{\mathrm{t}}^{2} A C_{\mathrm{D}}=m g,
$$

where $\rho_{\text {air }}$ is the air density, $A$ the cross-sectional area that the particle presents to the flow, $m$ the mass of the particle, and $g$ the acceleration due to gravity.

Therefore, the drag coefficient can be computed from Equation 1 as

$$
C_{\mathrm{D}}=\frac{2 m g}{\rho_{\text {air }} v_{\mathrm{t}}^{2} A} .
$$

Generally, $C_{\mathrm{D}}$ is a function of the Reynolds number, which is defined as

$$
R e=\frac{\rho_{\mathrm{air}} D v_{\mathrm{t}}}{\eta},
$$

where $\eta$ is the dynamic viscosity of the air.

Given that $C_{\mathrm{D}}$ and $R e$ depend on the terminal velocity, it is useful to compute the terminal velocity using the Best number, Be (Best, 1950),

$$
B e=C_{\mathrm{D}} R e^{2}=\frac{2 m g \rho_{\mathrm{air}} D^{2}}{\eta^{2} A} .
$$

As can be observed from Equation 4, the Best number only depends on the properties of ice particles ( $m, A$, and $D)$ and the properties of the air $\left(\rho_{\text {air }}\right.$ and $\left.\eta\right)$. Therefore, via a relationship between $B e$ and $R e$, the terminal velocity of ice crystals can be computed if these parameters are known.

The use of dimensionless numbers to study the sedimentation process reduces the number of combined variables that rule the problem and allows us to derive a scale law that represents the process (in this case a relationship between $B e$ and $R e$ ). However, in order to use this property, geometric, kinematic, and dynamic similarities are required. 

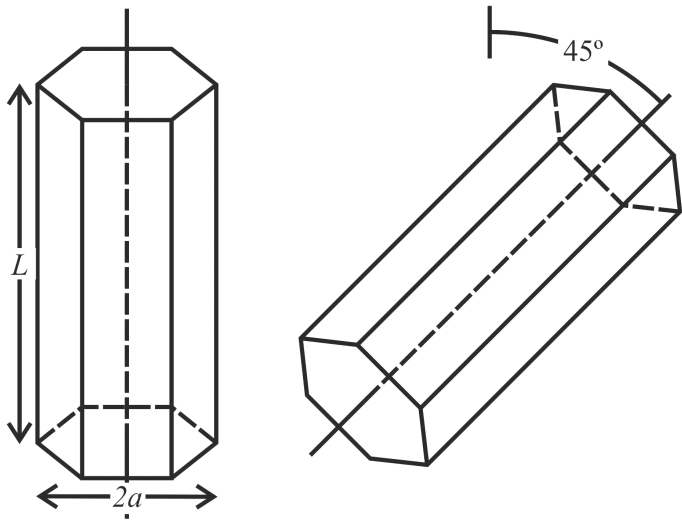

FI G URE 1 Rigid-body scheme used to represent a hexagonal columnar ice crystal in the LBM simulation, showing the different orientations (vertical, $45^{\circ}$, and horizontal) and body dimensions

\section{3 | DATA}

The numerical data used in the present study correspond to those reported by Giovacchini (2017) in his appendix B and some additional data obtained from new LBM simulation, presented in Table A1 in our Appendix. The terminal velocities of columnar ice crystals were used, with length $(L)$ between 20 and $90 \mu \mathrm{m}$ and aspect ratio (defined as the ratio between the length and the basal size of the columnar ice crystals, $a_{r}=L /(2 a)$, see Figure 1$)$ between 1 and 3 . The different values of aspect ratio used in the simulations were selected to be representative of the natural variability reported for columnar ice crystals (Baker and Lawson, 2006; Um et al., 2015), while the size range used represents the size of the ice crystals observed in cirrus clouds (Heymsfield, 1986; Jackson et al., 2015; Um et al., 2015; Luebke et al., 2016).

The simulations were made for different ice crystal densities $\left(\rho_{\text {ice }}\right)$ and three different orientations of the larger dimension of the ice crystal with respect to the falling direction (vertical, horizontal, and $45^{\circ}$ angle), as shown in Figure 1. Ice crystal densities were selected to represent the density reported by Ryan et al. (1976). The ice crystal orientations are based on the conclusion of Böhm (1991) and the experimental results presented by Bürgesser et al. (2016), who reported that, under low $R e(\operatorname{Re}<1)$, columnar ice crystals show a random orientation during free fall. Furthermore, remote-sensing observations of ice crystal orientation had shown a 50\% chance of horizontally oriented ice crystals at any height in the cloud (Thomas et al., 1990). Noel and Chepfer, 2004 (2004; 2010) reported that horizontally oriented ice crystals are almost nonexistent in optically thin ice clouds colder than $-30^{\circ} \mathrm{C}$, while horizontally oriented ice crystals represent less than $50 \%$ of the ice crystals present in warmer ice clouds. Given that the majority of ice particles present an irregular shape (Korolev et al., 1999; 2000), the remote sensing indicates that most of the natural ice particles, irregular and pristine, are not oriented. However, direct measurement of ice crystals imaged by a Cloud Particle Imager reported that only $\sim 30 \%$ of columns measured during the observations were horizontally oriented (Um et al., 2015). Finally, Sassen (1980) argued that the presence of small-scale turbulent air motions in the atmosphere can aid in the reorientation of ice crystals with $R e<1$ into random orientation.

Therefore, the horizontal and vertical orientations represent extreme cases for the falling orientations of ice crystals, while the $45^{\circ}$ angle was selected as an intermediate orientation to check the validity of the results. Given that ice crystals falling with horizontal and vertical orientation present the largest difference in cross-sectional area, these extreme orientations should present the largest difference in terminal velocities and the largest discrepancy with theoretical results.

As was reported by Giovacchini (2017), the fluid properties used in the simulation correspond to a temperature of $-8^{\circ} \mathrm{C}$ and an atmospheric pressure of $1.01325 \times 10^{5} \mathrm{~Pa}$.

\section{4 | RESULTS AND DISCUSSION}

\section{1 $\quad$ Characteristic length}

Figure 2 shows the Best number as a function of Reynolds number for columnar ice crystals falling with the three different orientations (black squares, open circles, and open triangles represent ice crystals with vertical, horizontal, and $45^{\circ}$ orientations, respectively). Be and $R e$ were computed using Equations 3 and 4, respectively. The cross-sectional area $A$ used in the calculations was the actual area that the ice crystals present to the flow. Table 1 shows the different characteristic lengths, defined by different authors, used in the present work to calculate the $R e$ and Be numbers shown in Figure 2.

As can be seen in Figure 2, the computed values of $R e$ are less than 1 and therefore correspond to a viscous flow regime. In this regime, Westbrook 
(a)

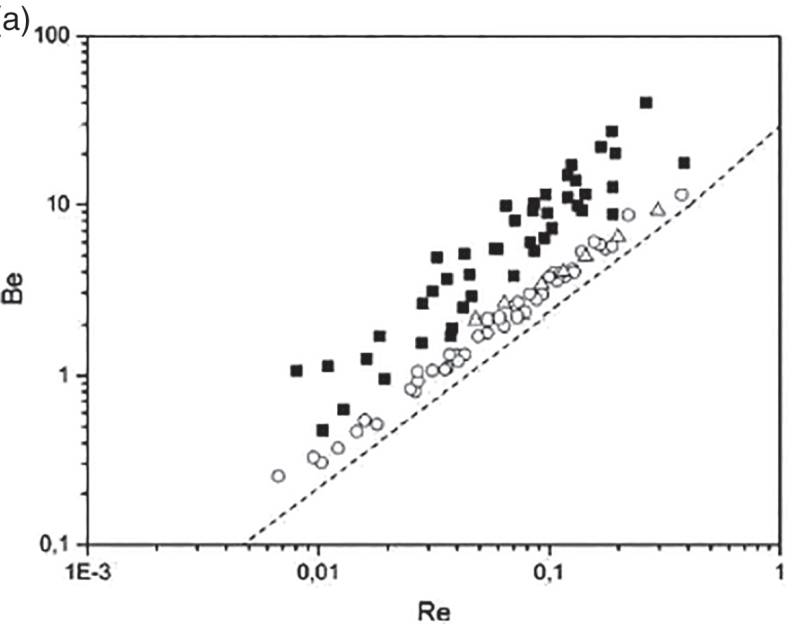

(c)

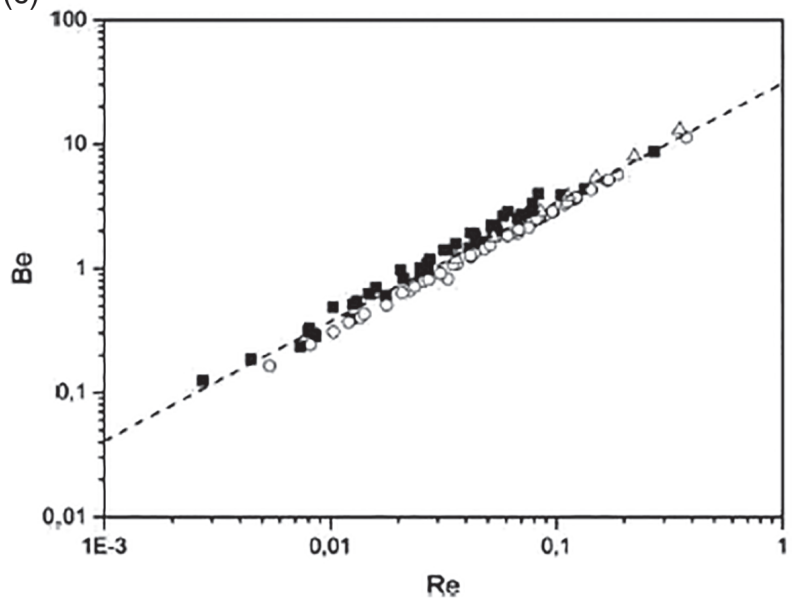

(b)

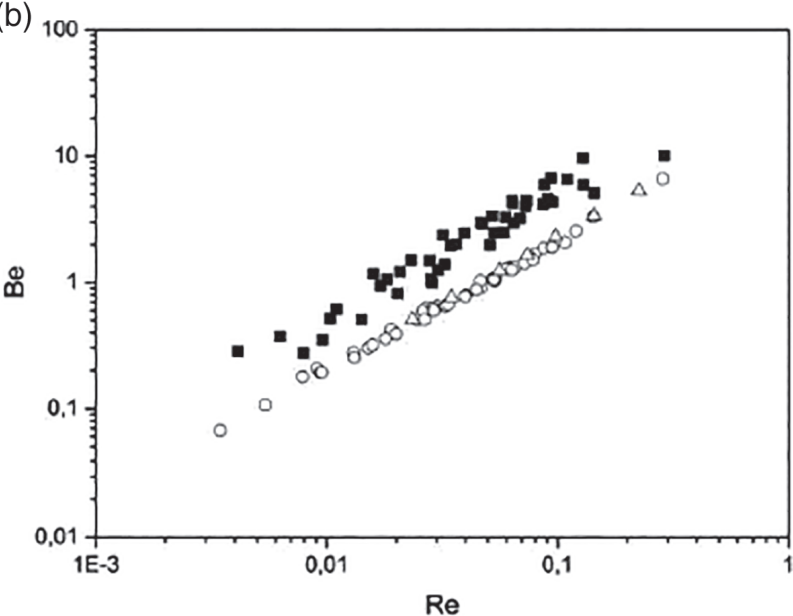

(d)

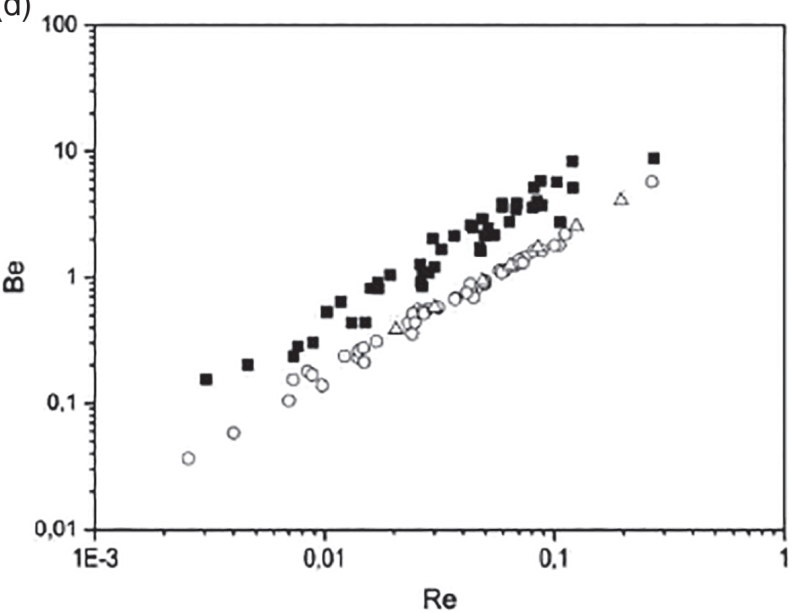

(e)

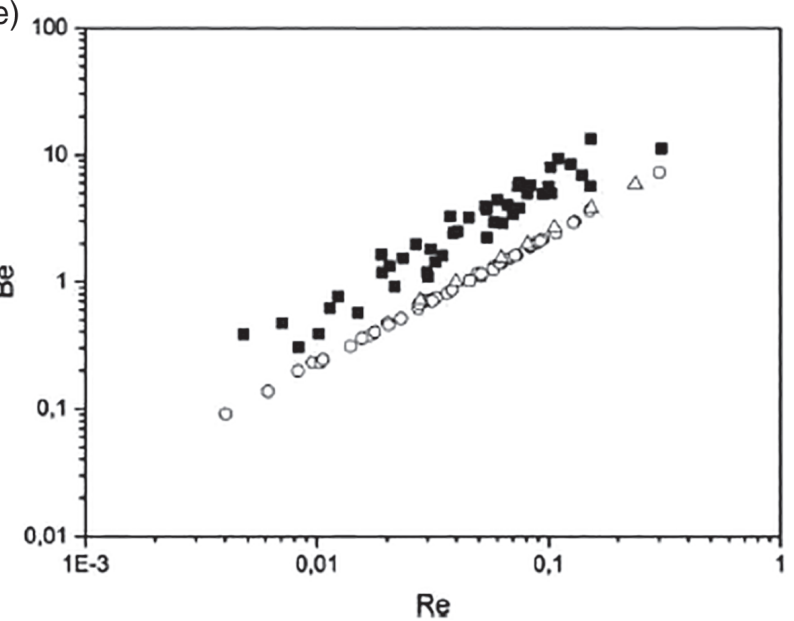

F I G U R E $2 B e$ versus Re, using as characteristic length (a) $D_{M}$, (b) $D_{B}$, (c) $D_{W}$, (d) $D_{\text {sph }}$, and (e) $D_{m}$. Black squares, open circles, and open triangles represent ice crystals with vertical, horizontal, and $45^{\circ}$ orientations, respectively. The broken line in panel (a) represents the Mitchell (1996) Be - Re proposal and the broken line in panel (b) represents the power law obtained by fitting the data

(2008) pointed out that the different theoretical formulations reported in the literature overestimate the terminal velocity.

The data show a behavior consistent with a power-law relationship between $B e$ and $R e$. However, the data are not well represented when different characteristic lengths are used. Ice crystals with vertical orientation (black squares) show a large dispersion, while ice crystals with horizontal and $45^{\circ}$ orientations seem to be better parametrized, with a unique $B e-R e$ relationship. Nevertheless, Figure 2 suggests that ice crystals with different orientations cannot be represented with a single $B e-R e$ parametrization 
TA B L E 1 Characteristic lengths used in the study

\begin{tabular}{lc} 
Characteristic length & Reference \\
\hline Maximum dimension of ice crystals: $D_{M}$ & Mitchell (1996) \\
\hline Diameter of the smallest circle or ellipse which completely contains $A: D_{B}$ & Böhm (1992) \\
\hline Ice crystal capacitance: $D_{W}$ & Westbrook (2008) \\
\hline Equivalent spherical diameter: $D_{\text {sph }}$ & Haider and Levenspiel (1989) \\
\hline Melted diameter: $D_{m}$ & \\
\hline
\end{tabular}

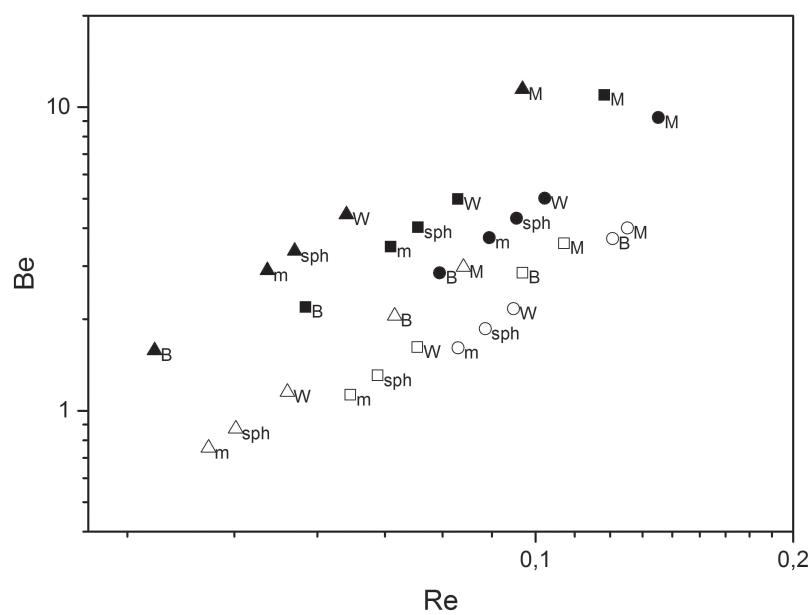

F I G U R E $3 \quad B e$ versus $R e$ for three different ice crystals. Each individual ice crystal is represented by the same symbol: circle

( $\rho_{\text {ice }}=800 \mathrm{~kg} \mathrm{~m}^{-3}, L=45 \mu \mathrm{m}$, and $a_{r}=1.5$ ), square

( $\rho_{\text {ice }}=800 \mathrm{~kg} \mathrm{~m}^{-3}, L=50 \mu \mathrm{m}$, and $a_{r}=2.0$ ) and triangle

( $\rho_{\text {ice }}=800 \mathrm{~kg} \mathrm{~m}^{-3}, L=52 \mu \mathrm{m}$, and $a_{r}=2.5$ ). Open and black

symbols represent horizontal and vertical orientation, respectively.

The characteristic lengths used to compute the values of $R e$ and $B e$ are indicated by the script next to each symbol

using any of the characteristic lengths reported in Table 1. This result is in agreement with the fact that the required geometric similarity is not fulfilled and therefore it is not possible to find a unique scale law that represents the sedimentation process (Weinheimer, 1987).

The discrepancy between the different orientations can be observed more clearly in Figure 3, which shows the impact of the different characteristic lengths considered on the values of $B e$ and $R e$. As can be observed in Figure 3, those ice crystals falling vertically (open symbols) present a larger dispersion than the ice crystals falling horizontally (black symbols), regardless of the characteristic length used in the Best and Reynolds number determinations. Also, it can be noticed that the dispersion depends not only on the orientation but also on the aspect ratio of the ice crystals.

The lowest data dispersion can be observed when $D_{B}$ is used as the characteristic length (Figure 2b). A power law between $B e$ and $R e$ was fitted using all the data

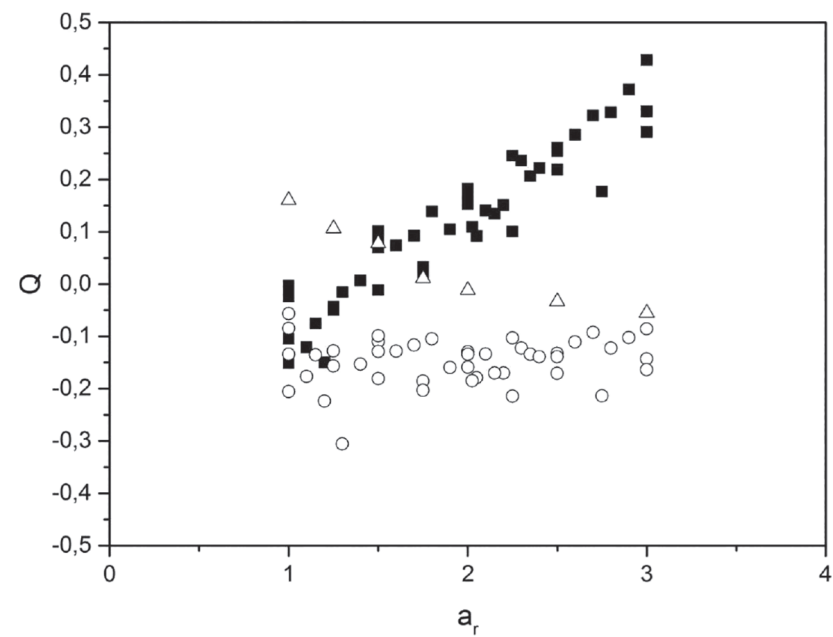

F I G U R E 4 Deviation, $Q$, of the computed terminal velocity as a function of the aspect ratio $a_{r}$ using $D_{B}$ as characteristic length. Black squares, open circles, and open triangles represent ice crystals with vertical, horizontal, and $45^{\circ}$ orientation, respectively

available (three orientations, represented by the dashed line in Figure $2 b$ ). The $B e-R e$ relationship found has the functional form $B e=10^{\alpha} R e^{\beta}$, where $\alpha=(1.49 \pm 0.02)$ and $\beta=(0.96 \pm 0.02)$ with $R^{2}=0.97313$. As can be observed, the power law shows good agreement with the data and shows a similar functional dependence on $R e$ as the Stokes solution for a sphere in a viscous flow regime.

From the relationship between $B e$ and $R e$, it is possible to compute the terminal velocity $\left(v_{\mathrm{c}}\right)$ of the ice crystals knowing the ice-crystal mass, its cross-sectional area, and the fluid properties. In order to evaluate the goodness of the $B e-R e$ relationship obtained, the deviation of the computed terminal velocity is defined as

$$
Q=\frac{\left(v_{\mathrm{c}}-v_{\mathrm{t}}\right)}{v_{\mathrm{t}}},
$$

where $v_{\mathrm{t}}$ is the terminal velocity obtained by LBM.

Figure 4 shows the value of $Q$, calculated using Equation 5, as a function of the ice-crystal aspect ratio $a_{r}$ for the computed velocity using $D_{B}$ as characteristic length. As can be observed, there is a strong dependence of $Q$ on $a_{r}$, particularly for those ice crystals that are falling with 


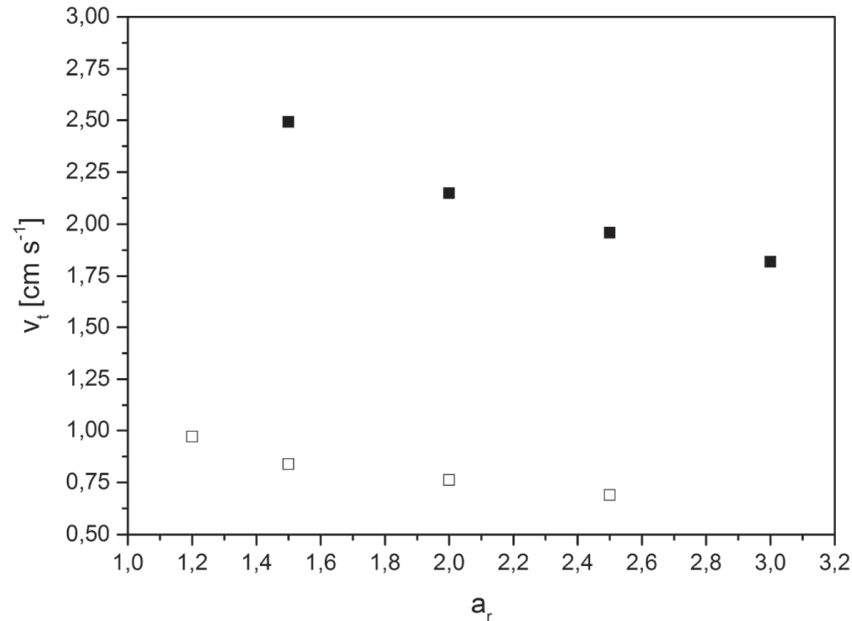

F I G U R E 5 Terminal velocity as a function of the aspect ratio $a_{r}$ for columnar ice crystals with vertical orientation. Black and open squares represent columnar ice crystals with $2 a=(50 / 3) \mu \mathrm{m}$ and $m=1.21 \times 10^{-11} \mathrm{~kg}$ and $2 a=25 \mu \mathrm{m}$ and $m=2.88 \times 10^{-12} \mathrm{~kg}$, respectively

vertical orientation. For ice crystals falling with horizontal orientation, $Q$ is negative, which indicates that the computed velocity is underestimated. The deviation is nearly constant and around $-15 \%$ for this orientation. For ice crystals falling with $45^{\circ}$ orientations, $Q$ is positive (which indicates that the computed velocity overestimates the terminal velocity) for $a_{r}$ less than 2 and negative for higher $a_{r}$, with an error of $20 \%$. For ice crystals falling with vertical orientations, $Q$ is positive for $a_{r}>1$ and shows a strong dependence on $a_{r}$, reaching an error of $40 \%$ for $a_{r} \sim 3$. These results suggest that the aspect ratio should be taken into account in order to have an accurate formulation of the terminal velocity.

In order to check these results, subsidiary experiments were performed where the terminal velocity was computed for columnar ice crystals with the same mass and cross-sectional area but with different $a_{r}$ (which implies different ice-crystal lengths). These new experiments were performed for ice crystals falling with vertical orientations and for two different sizes of the basal face and two different ice-crystal masses. Figure 5 shows the terminal velocity as a function of the aspect ratio for these subsidiary data. As can be observed, the terminal velocity decreases as $a_{r}$ increases. Given that the cross-sectional area and the mass are the same for each dataset, this result suggests that the area parallel to the flow could be relevant to ice-crystal motion.

According to the previous analysis, the best characteristic length that represents the sedimentation process is $D_{B}$. However, given that each group of subsidiary data presents the same projected area to the flow, $D_{B}$ will be the same for each group of data. Then, different values of
$R e$ (due to different velocities) will correspond to the same value of $B e$ number. Therefore, this result suggests that $D_{B}$ cannot be the characteristic length that describes the sedimentation process.

The impossibility of defining a characteristic length of columnar ice crystals is consistent with the fact that the law of similarity, established by fluid mechanics, is not applicable. The same value of Re establishes the same pattern of fluid flow as long as the same geometry of the body is maintained. Given that the subsidiary data had different lengths (but the same mass and cross-sectional area), the fluid pattern is different, resulting in different $R e$ values.

\section{2 $\quad B e-R e$ relationships}

Different relationships between $B e$ and Re were proposed in the literature. The relationships were obtained by fitting experimental data or based on boundary-layer theory (Abraham, 1970). Generally, in these formulations, the cross-sectional area $A$ in the Best number expression is parametrized by a characteristic length (Westbrook, 2008) or an effective area (Böhm, 1989, 2016; Heymsfield and Westbrook, 2010).

Figure 6a shows the deviation of the calculated velocity using the $B e-R e$ relationship proposed by Mitchell (1996) (broken line in Figure 2a). As was reported by Westbrook (2008), this formulation overestimates the terminal velocity of ice crystals for all orientations. In particular, for ice crystals falling with vertical orientation, the overestimation observed in Figure 6a reaches $\sim 500 \%$ for ice crystals with $a_{r} \sim 3$.

Heymsfield and Westbrook (2010) proposed a modified Best number $\left(B e^{*}\right)$, defined as

$$
B e^{*}=\frac{\rho_{\text {air }} 8 m g}{\eta^{2} \pi \sqrt{A_{r}}},
$$

where $A_{r}$ is the area ratio of the particle, defined as the ratio of the particle's projected area $A$ to the area of a circumscribing circle. Based on this approach, and on the results reported by Mitchell (1996), Heymsfield and Westbrook (2010) proposed a procedure to compute the terminal velocity. Figure $6 \mathrm{~b}$ shows the deviation of the computed terminal velocity using the method proposed by Heymsfield and Westbrook (2010) as a function of $a_{r}$. Using this new approach, the deviation is less than $10 \%$ for ice crystals with horizontal and $45^{\circ}$ orientations. However, for ice crystals falling with vertical orientation, the deviation shows a strong dependence on the aspect ratio, with $Q$ value of $20 \%$ for $a_{r} \sim 1$ and $80 \%$ for $a_{r} \sim 3$.

Westbrook (2008) suggests that, for nonspherical ice particles, a formulation should exist for the terminal 

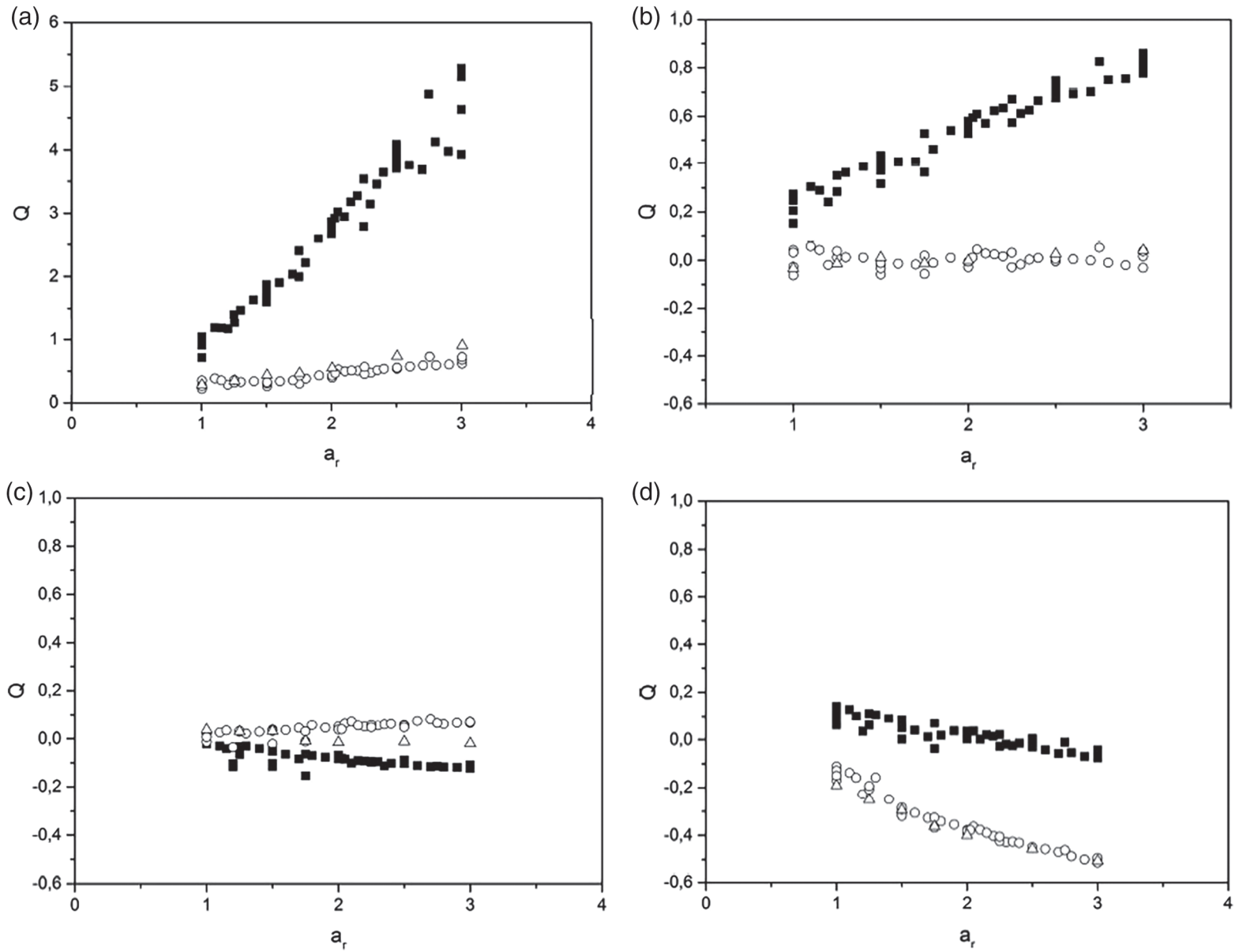

F I G U R E 6 Deviation, $Q$, of the computed terminal velocity as a function of the aspect ratio $a_{r}$ for (a) Mitchell (1996), (b) Heymsfield and Westbrook (2010), (c) Westbrook (2008), and (d) Böhm (1992) proposals. Black squares, open circles, and open triangles represent ice crystals with vertical, horizontal, and $45^{\circ}$ orientations, respectively

velocity similar to the Stokes solution for a sphere in a viscous flow, but using an effective hydrodynamic value for the ice-crystal radius. Based on the results reported by Hubbard and Douglas (1993), Westbrook (2008) proposed a quantity related to the capacitance of the ice crystals as their hydrodynamic radius. Figure $6 \mathrm{c}$ shows the deviation of the computed velocity, for the Westbrook (2008) proposal, using $D_{W}$ as the hydrodynamic radius of the columnar ice crystals. With this approach, the deviation is less than $20 \%$, as reported by Westbrook (2008). As can be observed, for ice crystals falling with horizontal orientation, the computed velocity overestimates the ice-crystal velocity, while for ice crystals falling with vertical orientation the computed velocity underestimates the ice-crystal velocity. However, in both cases, the deviation increases with aspect ratio.

As was found in previous analysis, these results suggest that the aspect ratio of ice crystals should be taken into account to compute the ice-crystal terminal velocity. Böhm (1992) proposed an improved expression for the general formula presented in Böhm (1989). In this formulation, the aspect ratio is included to obtain better accuracy in the calculations. Figure $6 \mathrm{~d}$ shows the deviation of the computed velocity obtained with the Böhm (1992) proposal. In this case, ice crystals with vertical orientation show lower deviation than ice crystals falling with horizontal and $45^{\circ}$ orientations. Nevertheless, all orientations show a deviation that depends on the aspect ratio.

All these results suggest that the dispersion in the computed terminal velocity reported in previous studies could be attributed not only to the dispersion reported in the experimental data or the lack of information on the governing variables. The different falling orientations and aspect ratios of the falling ice crystals cause an inherent dispersion in the data, which cannot be represented by a single characteristic length or otherwise overcome by means of the different formulations reported in the literature. The dispersion observed in the data is intrinsically related to the dimensionless variables $\left(R e, B e\right.$, and $\left.C_{\mathrm{D}}\right)$ used to parametrize the terminal velocity. Given that the drag force is associated with the interaction of the velocity field in the fluid with the moving particle, the drag force will be 

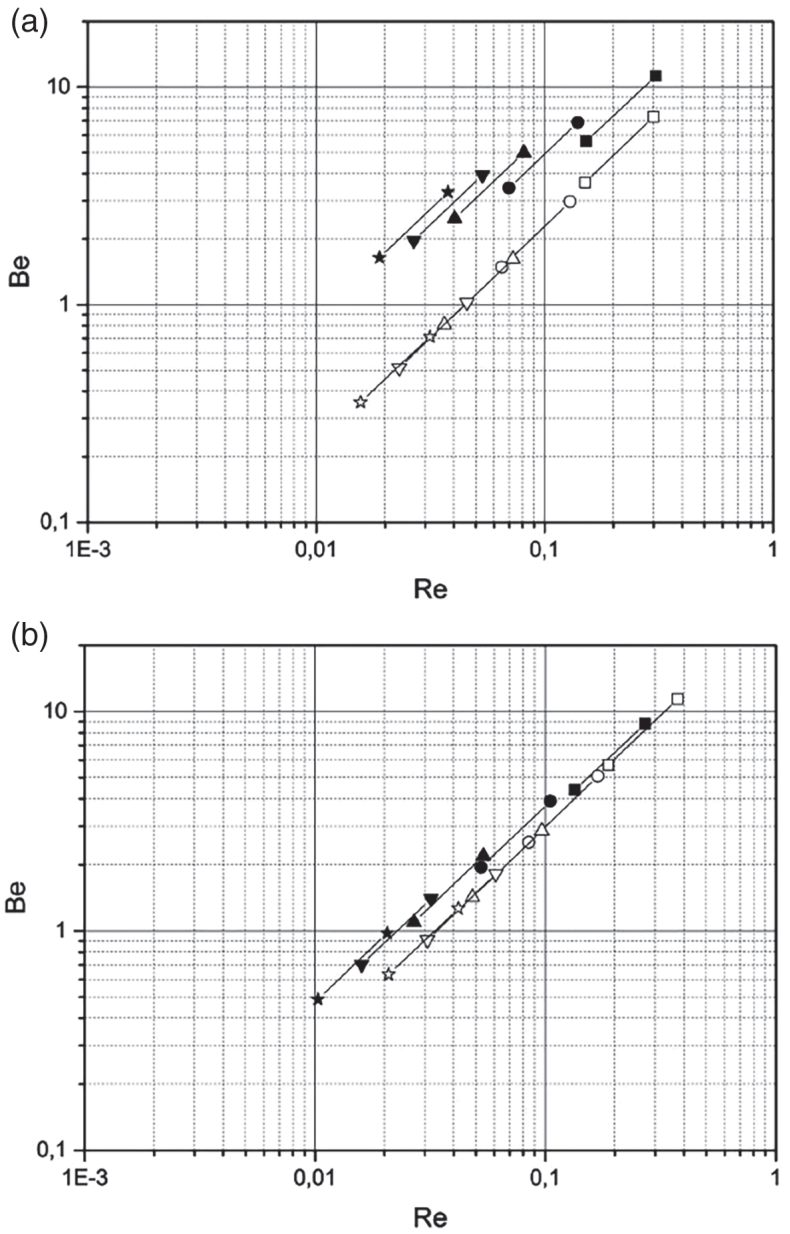

F I G U R E $7 \quad B e$ versus $R e$ for ice crystals using (a) $D_{W}$ and (b) $D_{B}$ as characteristic lengths. The squares, circles, up triangles, down triangles, and stars correspond to ice crystals with the same size but with $a_{r}$ of 1, 1.5, 2, 2.5, and 3, respectively. Symbols connected by a solid line represent ice crystals with the same $a_{r}$ but different mass. Black and open symbols represent ice crystals falling with vertical and horizontal orientations, respectively

different for falling ice crystals with different aspect ratios and different orientations.

\section{3 | Sensitivity of the $B e-R e$ relationship}

As was shown by Giovacchini (2017), the terminal velocity of ice crystals is governed primarily by the ice-crystal mass (Heymsfield, 1972; Heymsfield and Westbrook, 2010). Therefore, the uncertainty in this variable could lead to a large dispersion in the $\mathrm{Be}-\mathrm{Re}$ data. However, the different falling orientations of ice crystals also cause a large dispersion in the $B e-R e$ data, which is comparable with the dispersion generated by the uncertainty in ice-crystal mass.

Figure 7 shows $B e$ as a function of $R e$ for ice crystals with different mass and falling orientations using (a) $D_{W}$ and (b) $D_{B}$ as characteristic length. Data with the same symbol (squares, circles, up and down triangles, and stars) correspond to ice crystals with the same size but different $a_{r}$ and different ice bulk density. Symbols connected by a solid line represent ice crystals with the same size but different mass. Black and open symbols represent ice crystals falling with vertical and horizontal orientations, respectively.

As can be observed in Figure 7, for the same falling orientation, the values of $B e$ and $R e$ are duplicated when the ice-crystal mass is duplicated (symbols connected by a solid line), as expected. On the other hand, for ice crystals with the same mass but different orientations, the values of $B e$ and $R e$ increase around $20-30 \%$ when $D_{B}$ is used as characteristic length, and up to around $400 \%$ when $D_{W}$ is used as characteristic length. Therefore, these results suggest that the dispersions observed in $B e-R e$ data computed from experimental data are due not only to the uncertainty in the ice-crystal mass but also to a lack of knowledge of the ice-crystal falling orientation.

\section{5 | SUMMARY AND CONCLUSION}

The sedimentation process of columnar ice crystals was evaluated using data provided by the lattice Boltzmann method. An analysis of the sedimentation process of columnar ice crystals with different bulk densities and for different falling orientations was performed. The maximum dimension of the columnar ice crystals used in the analysis was less than $100 \mu \mathrm{m}$, with aspect ratios between 1 and 3. Three different orientations of the maximum dimension with respect to the vertical direction were taken into account for the analysis.

The velocities of the ice crystals obtained correspond to a viscous flow regime $(\operatorname{Re}<1)$ and the results show an overestimation of the terminal velocity of the ice crystals, as was previously reported by Westbrook (2008).

Different characteristic lengths of columnar ice crystals were evaluated in the analysis and the results suggest that it is not possible to define a unique characteristic length for the different orientations of the columnar ice crystals. Given that the geometry, kinetic, and dynamic similarities between falling particles with different orientations are not fulfilled, the sedimentation process cannot be parametrized by a unique $B e-R e$ relationship.

The use of a single $B e-R e$ relationship to compute the velocity of different columnar ice crystals could lead to large discrepancies between the computed and real velocities, which can cause an overestimation of the sedimentation process, particularly for columnar ice crystals falling with vertical orientation. The formulation proposed by Westbrook (2008) to compute the terminal velocity of 
columnar ice crystals in the viscous regime presents the lowest deviation in the computed velocities for the three different orientations studied. The deviation is less than $20 \%$ for aspect ratios less than 3 , but it has a dependence on the falling orientation of the ice crystals and a clear tendency to increase when the aspect ratio increases.

The characteristics (size, aspect ratio, density, and falling orientation) of the columnar ice crystals used in the simulation are representative of naturally occurring ice crystals observed in cirrus cloud. Although the majority of natural ice crystals present an irregular shape, the columnar ice crystal is one of the fundamental habits for smaller ice particles, and the results found should be taken into account in climate models. Given the sensitivity of these models to the ice process schemes occurring in cloud, there is a need for better accuracy in the ice process representation to obtain more realistic simulations. The inherent dispersion observed in the calculated terminal velocity by using a unique Best-Reynolds relationship could lead to mistaken cloud features. However, sensitivity tests should be performed in order to understand how the observed discrepancy affects the model results.

\section{ACKNOWLEDGEMENTS}

This work was supported by the Secretaría de Ciencia y Tecnología de la Universidad Nacional de Córdoba. We want to thank the anonymous referees for their most helpful comments and suggestions.

\section{REFERENCES}

Abraham, F.F. (1970) Functional dependence of drag coefficient of a sphere on Reynolds number. Physics of Fluids, 13, 2194-2195

Bailey, M. and Hallett, J. (2004) Growth rates and habits of ice crystals between $-20^{\circ}$ and $-70^{\circ} \mathrm{C}$. Journal of the Atmospheric Sciences, 61, 514-544

Baker, B.A. and Lawson, R.P. (2006) In situ observations of the microphysical properties of wave, cirrus, and anvil clouds. Part I: wave clouds. Journal of the Atmospheric Sciences, 63, 3160-3185

Baran, A.J. (2009) A review of the light scattering properties of cirrus. Journal of Quantitative Spectroscopy and Radiative Transfer, 110, $1239-1260$

Best, A.C. (1950) Empirical formulae for the terminal velocity of water drops falling through the atmosphere. Quarterly Journal of the Royal Meteorological Society, 76, 302-311

Böhm, H.P. (1989) A general equation for the terminal fall speed of solid hydrometeors. Journal of the Atmospheric Sciences, 46, 2419-2427

Böhm, J.P. (1991) Review of flow characteristics and kinematics of hydrometeors in free fall. Atmospheric Research, 26, 285-302

Böhm, J.P. (1992) A general hydrodynamic theory for mixed-phase microphysics. Part I: drag and fall speed of hydrometeors. Atmospheric research, 27, 253-274

Bürgesser, R.E., Ávila, E.E. and Castellano, N.E. (2016) Laboratory measurements of sedimentation velocity of columnar ice crystals. Quarterly Journal of the Royal Meteorological Society, 142, 1713-1720
Deng, M. and Mace, G.G. (2008) Cirrus cloud microphysical properties and air motion statistics using cloud radar doppler moments: water content, particle size, and sedimentation relationships. Geophysical Research Letters, 35, L17808. https://doi.org/10.1029/ 2008 GL035054.

Giovacchini, J.P. (2017) Sedimentation analysis of small ice crystals by the lattice Boltzmann method. Quarterly Journal of the Royal Meteorological Society, 143, 3085-3093

Haider, A. and Levenspiel, O. (1989) Drag coefficient and terminal velocity of spherical and nonspherical particles. Powder Technology, 58, 63-70

Heymsfield, A. (1972) Ice crystal terminal velocities. Journal of the Atmospheric Sciences, 29, 1348-1357

Heymsfield, A.J. (1986) Ice particles observed in a cirriform cloud at $-83^{\circ} \mathrm{C}$ and implications for polar stratospheric clouds. Journal of the Atmospheric Sciences, 43, 851-855

Heymsfield, A.J. (2007) On measurements of small ice particles in clouds. Geophysical Research Letters, 34, L23812. https://doi.org/ 10.1029/2007GL030951

Heymsfield, A.J. and Westbrook, C. (2010) Advances in the estimation of ice particle fall speeds using laboratory and field measurements. Journal of the Atmospheric Sciences, 67, 2469-2482

Hong, S.-Y., Dudhia, J. and Chen, S.-H. (2004) A revised approach to ice microphysical processes for the bulk parametrization of clouds and precipitation. Monthly Weather Review, 132, 103-120

Hubbard, J.B. and Douglas, J.F. (1993) Hydrodynamic friction of arbitrarily shaped Brownian particles. Physical Review E, 47, R2983

Jackson, R.C., McFarquhar, G.M., Fridlind, A.M. and Atlas, R. (2015) The dependence of cirrus gamma size distributions expressed as volumes in $\mathrm{N} 0-\lambda-\mu$ phase space and bulk cloud properties on environmental conditions: results from the small ice particles in cirrus experiment (SPARTICUS). Journal of Geophysical Research, 120, 351-10,377.

Jakob, C. (2002) Ice clouds in numerical weather prediction models. In D.K. Lynch, K. Sassen, D. O'C. Starr, and G. Stephens (Eds.), Cirrus (327-345). New York, NY: Oxford University Press.

Jayaweera, K. and Cottis, R. (1969) Fall velocities of plate-like and columnar ice crystals. Quarterly Journal of the Royal Meteorological Society, 95, 703-709

Jayaweera, K. and Ryan, B. (1972) Terminal velocities of ice crystals. Quarterly Journal of the Royal Meteorological Society, 98, 193-197

Kajikawa, M. (1971) A model experimental study on the falling velocity of ice crystals. Journal of the Meteorological Society of Japan II, 49, 367-375

Kajikawa, M. (1973) Laboratory measurement of falling velocity of individual ice crystals. Journal of the Meteorological Society of Japan II, 51, 263-272

Khvorostyanov, V.I. and Curry, J.A. (2002) Terminal velocities of droplets and crystals: power laws with continuous parameters over the size spectrum. Journal of the Atmospheric Sciences, 59, 1872-1884

Khvorostyanov, V.I. and Curry, J.A. (2005) Fall velocities of hydrometeors in the atmosphere: refinements to a continuous analytical power law. Journal of the Atmospheric Sciences, 62, 4343-4357

Korolev, A. (2011) Probe Tips for Airborne Instruments Used to Measure Cloud Microphysical Parameters. United States Patent No. 7861 584, Issued: 4 January, Owner: Her Majesty the Queen in Right of Canada, as Represented by The Minister of Environment 
Korolev, A., Isaac, G. and Hallett, J. (1999) Ice particle habits in Arctic clouds. Geophysical Research Letters, 26, 1299-1302

Korolev, A., Isaac, G. and Hallett, J. (2000) Ice particle habits in stratiform clouds. Quarterly Journal of the Royal Meteorological Society, 126, 2873-2902

Kraemer, M., Rolf, C., Luebke, A., Afchine, A., Spelten, N., Costa, A., Meyer, J., Zoeger, M., Smith, J., Herman, R.L., Buchholz, B., Ebert, V., Baumgardner, D., Borrmann, S., Klingebiel, M. and Avallone, L. (2016) A microphysics guide to cirrus clouds - Part 1: cirrus types. Atmospheric Chemistry and Physics, 16, 3463-3483

Lawson, R. (2011) Effects of ice particles shattering on the 2D-S probe. Atmospheric Measurement Techniques, 4, 1361-1381

Lawson, R., Woods, S., Jensen, E., Erfani, E., Gurganus, C., Gallagher, M., Connolly, P., Whiteway, J., Baran, A., May, P., Heymsfield, A., Schmitt, C., McFarquhar, G., Um, J., Protat, A., Bailey, M., Lance, S., Muehlbauer, A., Stith, J., Korolev, A., Toon, O.B., and Krämer, M. (2019) A review of ice particle shapes in cirrus formed in situ and in anvils. Journal of Geophysical Research:Atmospheres, 124, 10049-10090. https://doi.org/10.1029/2018JD030122

List, R. and Schemenauer, R.S. (1971) Free-fall behavior of planar snow crystals, conical graupel and small hail. Journal of the Atmospheric Sciences, 28, 110-115

Luebke, A.E., Afchine, A., Costa, A., Grooss, J.-U., Meyer, J., Rolf, C., Spelten, N., Avallone, L.M., Baumgardner, D. and Kraemer, M. (2016) The origin of midlatitude ice clouds and the resulting influence on their microphysical properties. Atmospheric Chemistry and Physics, 16, 5793-5809

Manning, K.W. and Davis, C.A. (1997) Verification and sensitivity experiments for the WISP94 MM5 forecasts. Weather and Forecasting, 12, 719-735

McFarquhar, G.M., Um, J., Freer, M., Baumgardner, D., Kok, G.L. and Mace, G. (2007) Importance of small ice crystals to cirrus properties: observations from the tropical warm pool international cloud experiment (TWP-ice). Geophysical Research Letters, 34, L13803. https://doi.org/10.1029/2007GL029865

Mitchell, D.L. (1996) Use of mass-and area-dimensional power laws for determining precipitation particle terminal velocities. Journal of the Atmospheric Sciences, 53, 1710-1723

Mitchell, D.L. and Heymsfield, A.J. (2005) Refinements in the treatment of ice particle terminal velocities, highlighting aggregates. Journal of the Atmospheric Sciences, 62, 1637-1644

Mitchell, D.L., Rasch, P., Ivanova, D., McFarquhar, G. and Nousiainen, T. (2008) Impact of small ice crystal assumptions on ice sedimentation rates in cirrus clouds and GCM simulations. Geophysical Research Letters, 35, L09806. htpps://doi.org/10.1029/ 2008GL033552

Noel, V. and Chepfer, H. (2004) Study of ice crystal orientation in cirrus clouds based on satellite polarized radiance measurements. Journal of the Atmospheric Sciences, 61, 2073-2081

Noel, V. and Chepfer, H. (2010) A global view of horizontally oriented crystals in ice clouds from cloud-aerosol lidar and infrared pathfinder satellite observation (CALIPSO). Journal of Geophysical Research, 115, D00H23. https://doi.org/10.1029/ 2009JD012365

Pruppacher, H.R. and Klett, J.D. (1997) Microphysics of Clouds and Precipitation: Reprinted 1980. 2nd edn. Dordrecht: Kluwer Academic, $954 \mathrm{p}$

Ryan, B., Wishart, E. and Shaw, D. (1976) The growth rates and densities of ice crystals between $-3{ }^{\circ} \mathrm{C}$ and $-21^{\circ} \mathrm{C}$. Journal of the Atmospheric Sciences, 33, 842-850
Sanderson, B.M., Piani, C., Ingram, W., Stone, D. and Allen, M. (2008) Towards constraining climate sensitivity by linear analysis of feedback patterns in thousands of perturbed-physics GCM simulations. Climate Dynamics, 30, 175-190

Sassen, K. (1980) Remote sensing of planar ice crystal fall attitudes. Journal of the Meteorological Society of Japan II, 58, 422-429

Spichtinger, P. and Gierens, K. (2009) Modelling of cirrus clouds - Part 1b: structuring cirrus clouds by dynamics. Atmospheric Chemistry and Physics, 9, 707-719

Thomas, L., Cartwright, J. and Wareing, D. (1990) Lidar observations of the horizontal orientation of ice crystals in cirrus clouds. Tellus B, 42, 211-216

Um, J., McFarquhar, G., Hong, Y., Lee, S., Jung, C., Lawson, R. and Mo, Q. (2015) Dimensions and aspect ratios of natural ice crystals. Atmospheric Chemistry and Physics, 15, 3933-3956

Voigt, C., Schumann, U., Minikin, A., Abdelmonem, A., Afchine, A., Borrmann, S., Boettcher, M., Buchholz, B., Bugliaro, L., Costa, A., Curtius, J., Dollner, M., Dörnbrack, A., Dreiling, V., Ebert, V., Ehrlich, A., Fix, A., Forster, L., Frank, F., Fütterer, D., Giez, A., Graf, K., Grooß, J., Groß, S., Heimerl, K., Heinold, B., Hüneke, T., Järvinen, E., Jurkat, T., Kaufmann, S., Kenntner, M., Klingebiel, M., Klimach, T., Kohl, R., Krämer, M., Krisna, T.C., Luebke, A., Mayer, B., Mertes, S., Molleker, S., Petzold, A., Pfeilsticker, K., Port, M., Rapp, M., Reutter, P., Rolf, C., Rose, D., Sauer, D., Schäfler, A., Schlage, R., Schnaiter, M., Schneider, J., Spelten, N., Spichtinger, P., Stock, P., Walser, A., Weigel, R., Weinzierl, B., Wendisch, M., Werner, F., Wernli, H., Wirth, M., Zahn, A., Ziereis, H., and Zöger, M. (2017) Ml-cirrus: The airborne experiment on natural cirrus and contrail cirrus with the high-altitude long-range research aircraft halo. Bulletin of the American Meteorological Society, 98, 271-288

Weinheimer, A.J. (1987) Application of the Stokes drag on spheroids to the drag on disks and cylinders. Journal of the Atmospheric Sciences, 44, 2674-2676

Westbrook, C. (2008) The fall speeds of sub-100 $\mu \mathrm{m}$ ice crystals. Quarterly Journal of the Royal Meteorological Society, 134, 1243-1251

Westbrook, C.D. and Illingworth, A.J. (2009) Testing the influence of small crystals on ice size spectra using doppler lidar observations. Geophysical Research Letters, 36, L12810. https.//doi.org/10.1029/ 2009GL038186.

How to cite this article: Bürgesser RE, Giovacchini JP, Castellano NE. Sedimentation analysis of columnar ice crystals in viscous flow regimes. Q.J.R. Meteorol. Soc. 2020;146:426-437. https://doi.org/10.1002/qj.3684

\section{APPENDIX: LBM RESULTS}

In this Appendix we present the LBM results shown in section 4. The results for horizontal and vertical orientation were reported in appendix B of Giovacchini (2017). The new and subsidiary results used in the present study are shown in Table A1. The tests labeled as Tests 8-13 correspond to the subsidiary results shown in Figure 5. 


\begin{tabular}{llllll} 
Test & $\rho_{\text {ice }}\left[\mathbf{k g ~ m}^{-3}\right]$ & $\boldsymbol{a}_{\boldsymbol{r}}$ & $\boldsymbol{L}[\boldsymbol{\mu m}]$ & $\boldsymbol{v}_{\mathbf{t}}\left[\mathrm{cm} \mathrm{s}^{-\mathbf{1}}\right]$ & Orientation \\
\hline 1 & 650 & 1.00 & 50 & 5.46 & $45^{\circ}$ \\
\hline 2 & 650 & 1.50 & 50 & 3.121 & $45^{\circ}$ \\
\hline 3 & 650 & 2.00 & 50 & 2.161 & $45^{\circ}$ \\
\hline 4 & 650 & 2.50 & 50 & 1.551 & $45^{\circ}$ \\
\hline 5 & 650 & 3.00 & 50 & 1.188 & $45^{\circ}$ \\
\hline 6 & 650 & 1.75 & 50 & 2.611 & $45^{\circ}$ \\
\hline 7 & 650 & 1.25 & 50 & 4.047 & $45^{\circ}$ \\
\hline 8 & 600 & 2.0 & 50 & 2.148 & Vertical \\
\hline 9 & 480 & 2.5 & 62.5 & 1.958 & Vertical \\
\hline 10 & 400 & 3.5 & 75 & 1.819 & Vertical \\
\hline 11 & 640 & 1.5 & 25 & 0.838 & Vertical \\
\hline 12 & 480 & 2.0 & $\frac{100}{3}$ & 0.762 & Vertical \\
\hline 13 & 384 & 2.5 & $\frac{125}{3}$ & 0.689 & Vertical \\
\hline
\end{tabular}

TA B L E A1 New and subsidiary LBM results for columnar ice crystals 